\title{
Fiscal Decentralization, Corruption and Urban-Rural Income Inequality: Evidence from China
}

\author{
Longlong Duan \\ School of Economics and Management, Southwest Jiaotong University, Chengdu, China \\ Email: duanlonglong2006@126.com
}

Received 2 July 2015; accepted 2 August 2015; published 5 August 2015

Copyright (C) 2015 by author and Scientific Research Publishing Inc. This work is licensed under the Creative Commons Attribution International License (CC BY). http://creativecommons.org/licenses/by/4.0/ c) (i) Open Access

\begin{abstract}
This paper follows fiscal federalism that a higher degree of fiscal decentralization is always associated with lower corruption and income inequality. There exists a stronger dynamic relationship among fiscal decentralization, corruption and income inequality in developing countries. Based on the panel dataset from 1999 to 2012 , this research is focusing on China, showing that it does not exist a simple linear relationship among fiscal decentralization, corruption and urban-rural income inequality, instead, the relationship between fiscal decentralization and urban-rural income inequality is more in line with a specific " $U$ " shape. While the effect of corruption on urban-rural income inequality, it can be gradually weakened as the reform of fiscal decentralization which expands the existed researches made by Mah (2013) and Lessmann (2010).
\end{abstract}

\section{Keywords}

Fiscal Decentralization, Corruption, Urban-Rural Income Inequality, Threshold Panel Model

\section{Introduction}

The second-generation theory of fiscal federalism pointed out that decentralization could effectively curb corruption (Oates, 2005; Bird, 2003; Lecuna, 2012 [1]) and it had been testified in most empirical researches (Albornoz, 2013 [2]; Lessmann, 2002 [3]; Fisman, 2002 [4]). The expenditure decentralization could strengthen the local bureaucratic competition while reduced the incidence of corruption efficiently by boosting the marketoriented reform (Zhou, 2004; Blackburn, 2009 [5]). Based on the studies on developing countries, bureaucratic corruption was the key factor for the income inequality, which behaved as the significant positive relationship (Dincer, 2012 [6]; Bin, 2013 [7]). Especially in the developing countries, the institutional root of income inequa- 
lity was corruption formed by the predatory ruling and market alternative resource allocation policy (Dobson, 2012 [8]). Although there exited extensive researches focusing on the relationship between fiscal decentralization and corruption, as well as how corruption affected income inequality. These researches failed to draw the consistent conclusion when discuss the relationship between fiscal decentralization and income inequality directly. Most cross-country studies approved that expenditure decentralization could narrow domestic income inequality (Gallo, 2011 [9]; Chen, 2009 [10]). However, the certain studies focusing on the developing countries always acquired the opposite conclusion or no relationship between them (Nayapti, 2006 [11]; Mah, 2012 [12]). Based on the research by Fan (2012), as the rapid transformation of economic structure and the promotion of market-oriented reform, there existed the nonlinear relationship between fiscal decentralization and income inequality in the developing countries especially in the empirical countries, which is corresponding to the research conducted by Zhang (2006) [13] focusing on China that income inequality was affected by Chinese-style decentralization through two aspects, which were regional governance capacity and investment expansion, respectively. Specifically, if the local government attached importance to the quality of governance, the income inequality would be reduced through strengthening the social service system. If not, the income inequality would be enlarged as the continuous expansion of the productive fiscal expenditure (mainly focusing on the urban infrastructure investment).

This study explored the effect of fiscal decentralization and corruption on urban-rural income inequality in China. More interestingly, there existed a significant nonlinear relationship among fiscal decentralization, corruption and urban-rural income inequity. Currently, In order to reverse the long-term tendency of the increasing urban-rural income inequity caused by bureaucratic corruption, the Chinese authority was devoting to reshape the decentralization system. It would provide valuable experiences for the development and transition of most developing countries. The rest of the paper was structured as follows. Section 2 described the econometric methodology, and Section 3 reported the empirical results while the final section was the conclusion.

\section{Data and Methodology}

This study employs static panel model and threshold panel model proposed by Hansen (2000) [14], respectively. Specifically, the sample set includes 31 provincial statistics of the Mainland China from the period of 1998-2011. The specification of static panel model can be described by Equation (1). Besides, the specification of threshold panel model can be shown by Equations (2) and (3), which fiscal decentralization and corruption are selected as the threshold variable to describe their influence on urban-rural income inequality.

$$
\begin{gathered}
I_{i t}=\alpha_{i}+X_{i t} \beta+\varepsilon_{i t} \\
I_{i t}=X_{i t} \beta+\lambda_{1} F D_{i t} G\left(F D_{i t} \leq \gamma_{1}\right)+\lambda_{2} F D_{i t} G\left(\gamma_{1} \leq F D_{i t} \leq \gamma_{2}\right)+\lambda_{3} F D_{i t} G\left(\gamma_{2} \leq F D_{i t}\right)+\mu_{i}+\varepsilon_{i t} \\
I_{\mathrm{it}}=X_{\mathrm{it}} \beta+\lambda_{1} C O_{\mathrm{it}} G\left(C O_{\mathrm{it}}<\gamma_{1}\right)+\lambda_{2} C O_{\mathrm{it}} G\left(\gamma_{1}<C O_{\mathrm{it}}<\gamma_{2}\right)+\lambda_{3} C O_{\mathrm{it}} G\left(\gamma_{2}<F D_{\mathrm{it}}\right)+\mu_{i}+\varepsilon_{\mathrm{it}}
\end{gathered}
$$

Specifically, in Equations (1), (2) and (3), focusing on the province i in the year of t, $I_{i t}$ denotes the urbanrural income inequality; $X_{i t}$ denotes other independent variables matrix affecting $I_{i t}$ except the threshold variables; $F D_{i t}$ describes the fiscal decentralization; $C O_{i t}$ denotes the incidence of corruption; $G$ denotes the indicative function; $\gamma$ is the value of threshold; both $\alpha_{i}$ and $\mu_{i}$ are the entity-fixed effect; $\varepsilon_{i t}$ is the random error term, which satisfies the assumption of classical linear regression.

In the estimation of statics panel model, 11 independent variables are incorporated, which are the incidence of corruption (CO), the decentralization of expenditure shares (FD), the size of government (GS), GDP per capita per year, the rate of urbanization (UR), market index (MI), the proportion of consumptive fiscal expenditure (CFE), openness indicator (OP), the proportion of state-owned economy in the industries (SOE), social consumption rate (CI) and industry softening coefficient (SIC). In China, the variable of CO always is substituted by the number of registered corruption cases of public servants per 10000 people per province while the government size is estimated through the number of public servants per million populations (Wu, 2010). For the variable of $I$, it can be computed by the ratio of urban residents' disposable income to rural residents' net income. In terms of the data source for all incorporated variables, except the incidence of corruption acquired through "Chinese Surveillance Yearbook" from 1999 to 2012, the others all come from "Chinese Statistical Yearbook" of corresponding year. During the process of estimation, in order to remove the negative effect of multicollinearity, stepwise regression is applied. In the meanwhile, to avoid spurious regression and improve the validity 
of parameter estimation, the process of logarithmic transformation is applied on both variables of government size and GDP per person per year. The specific estimation result for the static panel model can be seen in Table 1.

For China with rapid economic growth, threshold panel model proposed by Hensen $(1998,2000)$ enables to conduct the economic variable estimation under the condition of rapid regime transition. This study explores the variation of Chinese urban-rural inequality under decentralization transition and corruption transition, respectively. Specifically, under the condition of decentralization transition, the independent variables have been selected as GS, GDP per capita, UR and SOE. While under the condition of corruption transition, the independent variables can be selected as GS, MI, UI and SOE.

\section{Empirical Result}

For all these 5 models in Table 1, the statistics of Hausman test exceeds the critical value significantly, rejecting the specific hypothesis of random effect, denoting there exists significantly positive effect between UR, OP, SOE, CI, SIC and I. Based on the estimation of model 2 and 4 in Table 1, fiscal decentralization and urban-rural income inequality have the significant negative relationship. While GDP per capita on urban-rural income inequality is not clear. Moreover, based on the estimation of model 1 and 3, the expansion of government size is beneficial to the improvement of income inequality. If the decentralization is not considered, a proper degree of corruption is beneficial to reduce the income inequality. While under the endogeneity influence of corruption, the negative effect of governmental consumptive fiscal expenditure on reducing income inequality can be weakened. Furthermore, it can be shown that market-oriented resource allocation will intensify the income inequality while the Matthew effect through the specific reform can be offset by revenue redistribution regulating effect through the fiscal decentralization.

In conclusion, the Chinese fiscal decentralization aiming to expand the expenditure shares and intensify the quality of local public goods supply is beneficial to balance the income between urban and rural residents.

Table 1. OLS estimation results for static panel model.

\begin{tabular}{|c|c|c|c|c|c|}
\hline Dependent variable: $I$ & 1 & 2 & 3 & 4 & 5 \\
\hline Constant & $0.23(0.33)$ & $-1.6^{* *}(-2.44)$ & $-0.99^{*}(-1.67)$ & $-2.09^{* * *}(-3.8)$ & $-2.47^{* * *}(-4.85)$ \\
\hline Co & $-0.07(-1.59)$ & $0.09^{* *}(1.96)$ & $-0.1^{* *}(-2.03)$ & & \\
\hline FD & $-2.91^{*}(-1.61)$ & $-3.83^{*}(-1.90)$ & $-2.3(-1.2)$ & $-3.54^{* *}(-1.83)$ & \\
\hline LnGS & $-1.1^{* * *}(-8.76)$ & & $-0.91^{* * *}(-7.4)$ & $-0.91^{* * *}(-7.58)$ & \\
\hline LnGDP & $-0.04(-0.54)$ & $-0.2^{* *}(-2.73)$ & & $0.18^{* * *}(3.31)$ & \\
\hline UR & $1.6^{* * *}(4.59)$ & $1.78^{* * *}(4.65)$ & $2.25^{* * *}(6.71)$ & $1.76^{* * *}(4.76)$ & $1.06^{* * *}(3.37)$ \\
\hline MI & $0.07^{* * *}(4.99)$ & $0.06^{* * *}(4.06)$ & & & $0.02^{* *}(2.14)$ \\
\hline $\mathrm{CFE}$ & $0.27(1.5)$ & $-0.01(-0.07)$ & $0.37^{* *}(2.2)$ & & $-0.35^{* *}(-2.16)$ \\
\hline $\mathrm{OP}$ & $0.17^{* *}(2.55)$ & $0.10(1.45)$ & $0.29^{* * *}(4.43)$ & $0.28^{* * * *}(4.27)$ & $0.09(1.45)$ \\
\hline SOE & $0.93^{* * *}(6.14)$ & $0.54^{* * *}(3.60)$ & $0.91^{* * * *}(5.96)$ & $0.88^{* * * *}(5.79)$ & $0.48^{* * *}(3.27)$ \\
\hline CI & $0.35(1.41)$ & $0.16(0.61)$ & $0.52^{* * *}(2.2)$ & $0.79^{* * *}(3.2)$ & $0.69^{* * *}(2.83)$ \\
\hline SIC & $6.19^{* * * *}(11.27)$ & $5.58^{* * *}(9.48)$ & $6.46^{* * *}(12.2)$ & $5.66^{* * * *}(10.59)$ & $5.11^{* * *}(9.39)$ \\
\hline Hausman Test & $\mathrm{FE}$ & $\mathrm{FE}$ & $\mathrm{FE}$ & $\mathrm{FE}$ & $\mathrm{FE}$ \\
\hline Adjusted-R ${ }^{2}$ & 0.925 & 0.91 & 0.92 & 0.92 & 0.92 \\
\hline F-statistic & $132.1^{* * *}$ & $113.9^{* * *}$ & $130.6^{* * *}$ & $131.3^{* * *}$ & $132.4^{* * *}$ \\
\hline
\end{tabular}

Notes: ${ }^{* * *}$ and ${ }^{* * *}$ indicate the significant level at $10 \%, 5 \%$ and $1 \%$, respectively; FE denotes the fix effect. 
However, as the different incentive effect of decentralization on the behavior of the government bureaucracy, the effect of corruption on urban-rural income inequality is not clear, denoting there exist the complex interactions between fiscal decentralization and corruption during Chinese transition period. Hence, it is unreliable that there exist sample linear effects of both Chinese fiscal decentralization and corruption on urban-rural income inequality.

In Table 2 and Table 3, the nonlinear effect of fiscal decentralization and corruption on urban-rural income inequality has been testified. Moreover, there exists the " $U$ " shaped relationship between fiscal decentralization and urban-rural income inequality while fiscal decentralization has two threshold estimates ( $\gamma=0.011$ and $\gamma=0.028$, respectively). Simultaneously, the positive threshold effect can be obtained between corruption and income inequality, denoting corruption incidence also has two threshold estimates ( $\gamma=3.22$ and $\gamma=3.57$, respectively). Although there exists the positive relationship between corruption and income inequality through the sign of parameters, this positive relationship will be weakened sharply with the accumulation of corruption. Finally, it has been proved that the variables such as GS, UR, GDP per capita, MI and SOE are the main contributors to this nonlinear change. Specifically, the government expansion elastic effect is the most beneficial factor to narrow the income gap. While the marketization forces and nationalization trend will further contribute to the alienation of urban-rural income.

\section{Conclusion}

This paper explores the direct relationship among decentralization of expenditure shares, corruption and urbanrural income inequality in China. Specifically, the existence of nonlinear effect of decentralization and corruption on urban-rural income inequality has been testified through this study. In the meanwhile, there are two important findings in this paper. Firstly, under the background of rapid transition of Chinese economic system, the expansion of state-owned economy has become one of the reasons that intensify the urban-rural income inequa-

Table 2. Estimation for threshold panel model (Fiscal decentralization as the threshold variable).

\begin{tabular}{ccc}
\hline Dependent Variable: $I$ & Parameter & T-Value \\
\hline LnGS & $-1.32^{* * *}$ & -7.05 \\
LnGDP & $0.28^{* * *}$ & 4.69 \\
UR & $2.92^{* * * *}$ & 6.44 \\
SOE & $0.69^{* * * *}$ & 3.73 \\
$F D(\gamma \leq 0.011)$ & $-17.58^{*}$ & -1.79 \\
$F D(0.011<\gamma \leq 0.028)$ & $10.31^{* * *}$ & 3.22 \\
$F D(\gamma>0.028)$ & $4.20^{*}$ & 1.71 \\
\hline
\end{tabular}

Notes: ${ }^{* * *}$ and ${ }^{* * *}$ indicate the significant level at $10 \%, 5 \%$ and $1 \%$, respectively.

Table 3. Estimation for threshold panel model (Corruption incidence as the threshold variable).

\begin{tabular}{clc}
\hline Dependent Variable: $I$ & Parameter & T-Value \\
\hline LnGS & $-0.81^{* * * *}$ & -4.38 \\
UR & $3.06^{* * *}$ & 6.37 \\
MI & $0.08^{* * *}$ & 5.24 \\
SOE & $0.61^{* * *}$ & 2.93 \\
LnCor $(\gamma \leq 3.22)$ & $0.36^{* * *}$ & 3.23 \\
LnCor $(3.22<\gamma \leq 3.57)$ & $0.32^{* * *}$ & 3.07 \\
LnCor $(\gamma>3.57)$ & $0.28^{* * *}$ & 2.94
\end{tabular}

Notes: ${ }^{*},{ }^{* *}$ and ${ }^{* * *}$ indicate the significant level at $10 \%, 5 \%$ and $1 \%$, respectively. 

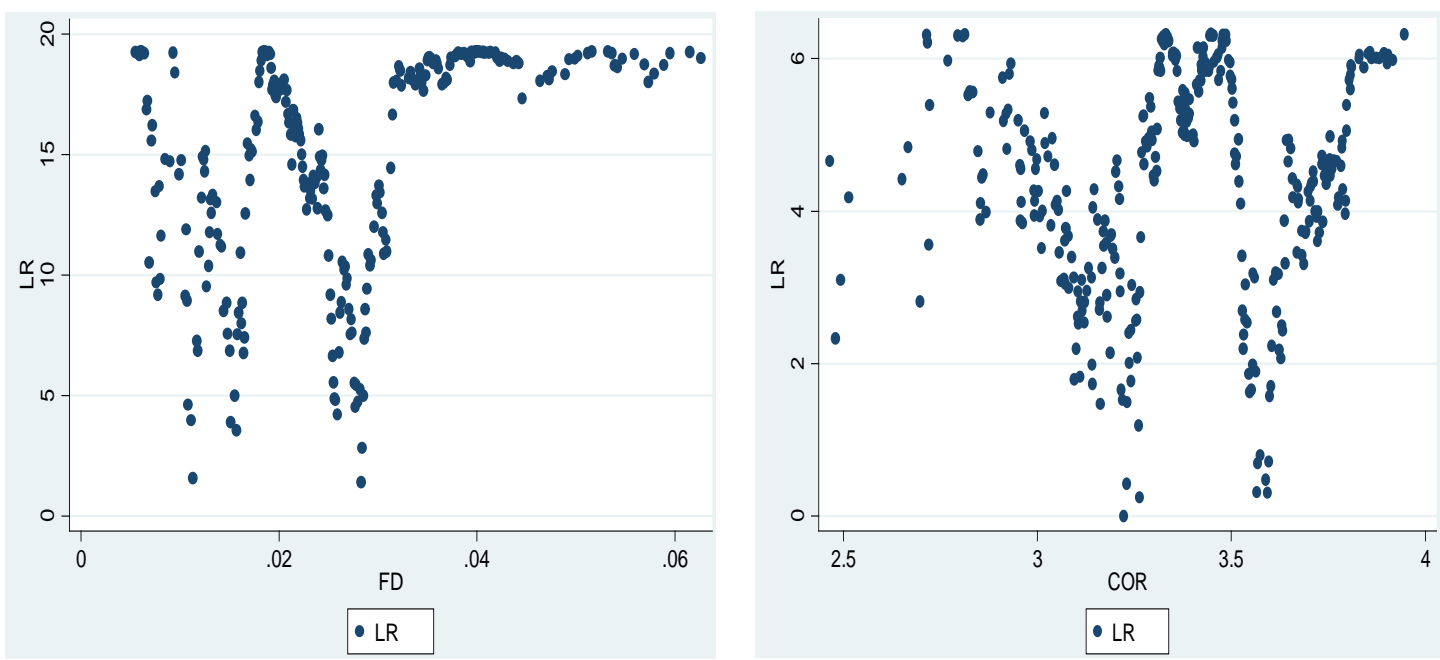

Figure 1. LR value for threshold panel model. (The ratio of disposable income between urban and rural residents as the dependent variable).
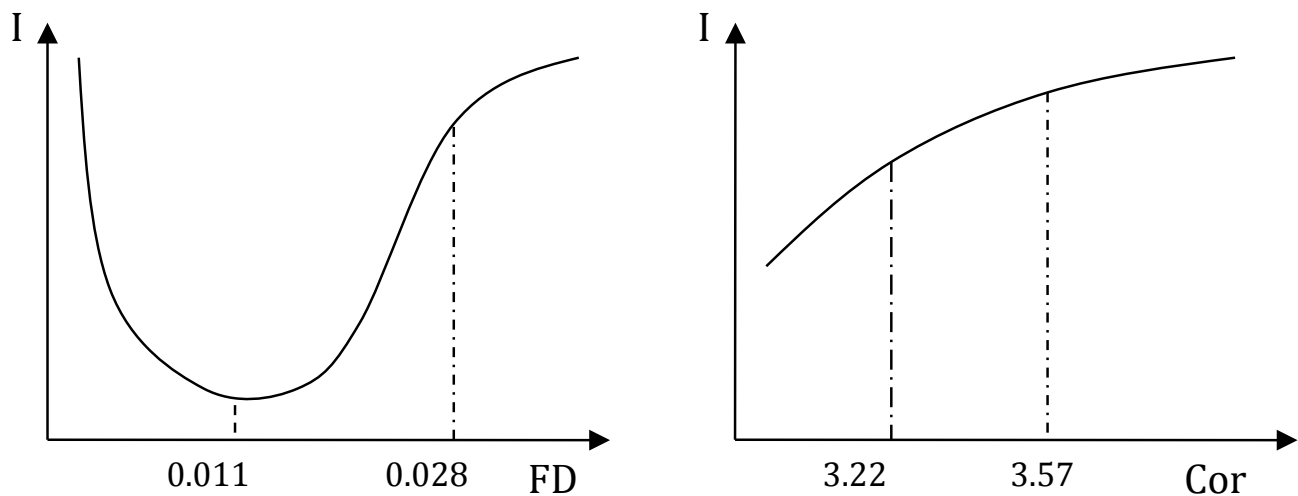

Figure 2. Relationship between fiscal decentralization, Corruption and income inequality in China.

lity and market monopoly. Secondly, although corruption is the common social problem facing by most developing countries, in China, the effect of corruption on urban-rural income inequality is gradually weakening. In the future, the relevant policies should be made following the idea of fiscal federalism to improve the quality of public goods supply through decentralization. Finally, the "U" structure of urban-rural income inequality can also be crossed (See Figure 1 and Figure 2).

\section{References}

[1] Lecuna, A. (2012) Corruption and Size Decentralization. Journal of Applied Economics, 115, 139-168. http://dx.doi.org/10.1016/S1514-0326(12)60007-5

[2] Albornoz, F. and Cabrales, A. (2013) Decentralization, Political Competition and Corruption. Journal of Development Economics, 105, 103-111. http://dx.doi.org/10.1016/j.jdeveco.2013.07.007

[3] Lessmann, C. and Markwardt, G. (2010) One Size Fits All? Decentralization, Corruption, and the Monitoring of Bureaucrats. World Development, 38, 631-646. http://dx.doi.org/10.1016/j.worlddev.2009.11.003

[4] Fisman, R. and Gatti, R. (2002) Decentralization and Corruption: Evidence across Countries. Journal of Public Economics, 83, 325-345. http://dx.doi.org/10.1016/S0047-2727(00)00158-4

[5] Blackburn, K. and Forgues-Puccio, G.F. (2009) Why Is Corruption Less Harmful in Some Countries than in Others? Journal of Economic Behavior \& Organization, 77, 797-810. http://dx.doi.org/10.1016/j.jebo.2009.08.009

[6] Dincer, O.C. and Gunalp, B. (2012) Corruption and Income Inequality in the United States. Contemporary Economic Policy, 30, 283-292. http://dx.doi.org/10.1111/j.1465-7287.2011.00262.x

[7] Bin, D. and Torgler, B. (2013) Causes of Corruption: Evidence from China. China Economic Review, 26, $152-169$. 
http://dx.doi.org/10.1016/j.chieco.2012.09.005

[8] Dobson, S. and Ramlogan, C. (2012) Why Is Corruption Less Harmful to Income Inequality in Latin America? World Development, 40, 1534-1545. http://dx.doi.org/10.1016/j.worlddev.2012.04.015

[9] Muinelo-Gallo, L. and Oca-Sagales, O. (2011) Economic Growth and Inequality: The Role of Fiscal Policies. Australian Economic Papers, 4, 221-243. http://dx.doi.org/10.1111/j.1467-8454.2011.00412.x

[10] Chen, L. and Zhang, D. (2009) Trade Liberalization and Urban Poverty in China. Journal of International Trade, 35, 32-38.

[11] Neyapti, P. (2006) Revenue Decentralization and Income Distribution. Economics Letters, 92, 409-416. http://dx.doi.org/10.1016/j.econlet.2006.03.026

[12] Mah, J.S. (2013) Globalization, Decentralization and Income Inequality: The Case of China. Economic Modelling, 31, 653-658. http://dx.doi.org/10.1016/j.econmod.2012.09.054

[13] Zhang, X. (2006) Fiscal Decentralization and Political Centralization in China: Implications for Growth and Inequality. Journal of Comparative Economics, 34, 713-726. http://dx.doi.org/10.1016/j.jce.2006.08.006

[14] Hansen, B.E. (2000) Sample Splitting and Threshold Estimation. Econometrica, 68, 575-603. http://dx.doi.org/10.1111/1468-0262.00124 